\title{
Antitumor activity of an adenovirus harboring two therapeutic genes, anti-VEGF ribozyme and human IL-24, in colon cancer
}

\author{
SHUJIAN CHANG ${ }^{1,3}$, WEICHANG CHEN ${ }^{1}$, JICHENG YANG $^{2}$, YUFENG XIE ${ }^{2}$ and WEIHUA SHENG ${ }^{2}$ \\ ${ }^{1}$ Department of Gastroenterology, The First Affiliated Hospital, Soochow University, Suzhou 215006; \\ ${ }^{2}$ Cell and Molecular Biology Institute, College of Medicine, Soochow University, Suzhou 215132; \\ ${ }^{3}$ Department of Oncology, the Fourth Affiliated Hospital, Soochow University, Wuxi 214062, P.R. China
}

Received December 29, 2008; Accepted June 3, 2009

DOI: 10.3892/mmr_00000158

\begin{abstract}
Increased vascular endothelial growth factor (VEGF) expression and tumor vascularization are correlated with both tumor progression and a poor clinical prognosis in colon cancer. There is increasing evidence that mda-7/IL-24 has potent growth suppression activity and induces apoptosis in many different tumor cells. We constructed a recombinant replication-deficient adenovirus carrying both an anti-VEGF hairpin ribozyme and human IL-24 (Ad-Rz/IL-24) with an internal ribosome entry site and tested its VEGF inhibition effect and antitumor activity. The results showed that Ad-Rz/ IL-24 significantly inhibited VEGF expression and angiogenesis in vitro and in vivo. The proliferation rate of xenograft tumors treated with Ad-Rz/IL-24 was approximately 50\% lower than the rate of the xenograft tumors treated with adenovirus carrying a single gene anti-VEGF hairpin ribozyme (Ad-Rz) or IL-24 (Ad-IL-24) alone. These findings demonstrated the potential therapeutic effect of this dual gene-expressing adenovirus for cancer gene therapy.
\end{abstract}

\section{Introduction}

Despite significant improvements in the diagnosis and therapy of colon cancer, the current treatment for colon cancer is still unsatisfactory, particularly for relapsed and metastatic patients. Therefore, innovative therapeutic strategies are necessary.

Tumor growth and metastasis are dependent on angiogenesis $(1,2)$. Research investigating the molecular basis of angiogenesis has identified multiple factors that contribute to tumor angiogenesis, including vascular endothelial growth factor (VEGF), fibroblast growth factor and platelet-derived

Correspondence to: Dr Weichang Chen, Department of Gastroenterology, The First Affiliated Hospital, Soochow University, Suzhou 215006, P.R. China

E-mail: weichangchen@126.com

Key words: anti-VEGF hairpin ribozyme, mda-7/IL-24, adenoviral vector, gene therapy growth factor (3). Among these factors, VEGF plays a key role in tumor angiogenesis. In general, VEGF is commonly upregulated in colon cancer, and increased VEGF expression and tumor vascularization (e.g., increased microvessel density) are correlated with tumor progression and a poor clinical prognosis in colon cancer. Colon cancer represents one of the best studied models of tumor angiogenesis (4-6). The downregulation of VEGF has therefore been an approach for colon cancer treatment.

mda-7/IL-24 (melanoma differentiation-associated gene 7) is a member of the IL-10 subfamily (7). It was first identified by subtraction hybridization in human melanoma cells induced for irreversible growth arrest and terminal differentiation by combined treatment with IFN- $\beta$ and MEZ (8). When expressed at high levels, mda-7/IL-24 suppresses growth and induces programmed cell death (apoptosis) in a broad spectrum of human cancers, including colon cancer. In contrast, mda-7/ IL-24 does not induce apoptosis in, and has a negligible effect on the growth of, normal cells $(9,10)$. This broad-spectrum antitumor activity of mda-7/IL-24 can be distinguished from other extensively studied tumor suppressor genes, and its growth-inhibition properties are independent of the status of $\mathrm{p} 53, \mathrm{pRB}, \mathrm{p} 21$ or additional tumor suppressor genes in cancer cells (11-13). mda-7/IL-24 is another anti-angiogenic factor. Its anti-angiogenic activity is even stronger than that of endostatin, IFN- $\gamma$ or IP-10 (interferon-inducible protein-10), whose angiogenic inhibitory activity has been previously demonstrated $(14,15)$.

It is hypothesized that combined treatment with IL-24 and VEGF inhibition is more effective against colon cancers than treatment with IL-24 or VEGF inhibition alone, particularly for those patients with invasive or metastatic tumors in which there is active angiogenesis.

Currently, recombinant adenoviruses are extensively used as vectors for cancer gene therapy, but can sometimes result in adverse events. In this study, in order to reduce the number of adenovirus particles and improve the transduction efficacy of therapeutic genes in gene therapy, we constructed an adenovirus that simultaneously expresses a cytomegalovirus (CMV) promoter-driven anti-VEGF hairpin ribozyme and human IL-24. These two genes are linked by an internal ribosome entrance site (IRES). The antitumor efficacy of the virus against HT-29 human colon cancer cells was examined. 


\section{Materials and methods}

Cell lines and culture conditions. The human colon cancer cell line HT-29 was used since it expresses a high level of VEGF and VEGFR (16). No IL-24 expression was detected by RT-PCR or immunofluorescence analysis in this cell line (see below). The cells were cultured in RPMI-1640 medium, supplemented with $10 \%$ fetal calf serum in a humidified atmosphere containing $5 \% \mathrm{CO}_{2}$ at $37^{\circ} \mathrm{C}$. The medium was purchased from Gibco BRL-Life Science Technologies Inc. and the serum was from Serabio Co., Ltd. (Hangzhou, China).

Generation of the recombinant adenoviral vectors. The recombinant adenoviruses were constructed following a previously described procedure (17). In this study, we constructed two replication-deficient adenoviral vectors: an adenovirus expressing an anti-VEGF hairpin ribozyme (Ad-Rz) and an adenovirus simultaneously expressing anti-VEGF hairpin ribozyme and human IL-24 (Ad-Rz/IL-24). The adenovirus expressing human IL-24 (Ad-IL-24) was constructed by the Cell and Molecular Biology Institute of Soochow University (18). The anti-VEGF hairpin ribozyme, designed according to a previously described principle (19), hybridizes to positions 1162-1175 of VEGF165 mRNA and cleaves the mRNA at site 1167 (G). The oligonucleotide fragment of the anti-VEGF ribozyme for Ad-Rz was constructed from two synthesized oligonucleotides: 5'-GATCTCTGATAAGAATCCAACCAG AGAAACACACGTTGTGGTATATTACCTGGTAGG-3' and 5'-TCGACCTACCAGGTAATATACCACAACGTGTGTT TCTCTGGTTGGATTCTTATCAGA-3'. These oligonucleotide sequences, which include BglII and SalI linker sites at each end, were inserted into the multiple cloning site (MCS) of the pTrack-CMV shuttle plasmid downstream of the CMV promoter. In Ad-Rz/IL-24, the anti-VEGF ribozyme was also inserted between the $B g l \mathrm{II}$ and SalI sites of pTrack-CMV, which harbored an IRES between the SalI and NotI digestion sites and human IL-24 cDNA between the XhoI and XbaI sites (previously constructed by the Cell and Molecular Biology Institute of Soochow University). Anti-VEGF ribozyme and human IL-24 cDNA were linked through an IRES (Fig. 1). The sequence of each plasmid was confirmed by direct sequencing. The resultant shuttle vector (pAdTrack-CMV-Rz/ IL-24 or pAdTrack-CMV-Rz) was linearized by the restriction endonuclease PmeI and subsequently co-transformed into BJ5183 bacterial cells with the adenoviral backbone plasmid (pAdEasy-1). After PacI digestion, the recombinant pAd-Rz/ IL-24 or pAd-Rz plasmid was transfected into human embryonic kidney 293 (QBI-293A) cells with Lipofectamine (Sigma, CA, USA) to package the viruses. The constructed adenoviruses were amplified in QBI-293A cells, purified by cesium chloride centrifugation and stored at $-80^{\circ} \mathrm{C}$ until use.

Analysis of the transduction efficiency of adenoviral vectors. To assess the ability of the adenoviral vector to infect HT-29 cells, cells were infected with vacant adenovirus (Ad-GFP). HT-29 cells were seeded in 6-well plates, and the cells were counted 24 h later. The virus Ad-GFP was diluted to 1, 10, 20 and 50 MOI (multiplicity of infection) per cell in $1 \mathrm{ml}$ RPMI1640 medium with $2 \%$ FBS added to each well and incubated at $37^{\circ} \mathrm{C}$ for $2 \mathrm{~h}$ with $3-5$ brief agitations; then, $2 \mathrm{ml}$ RPMI-1640

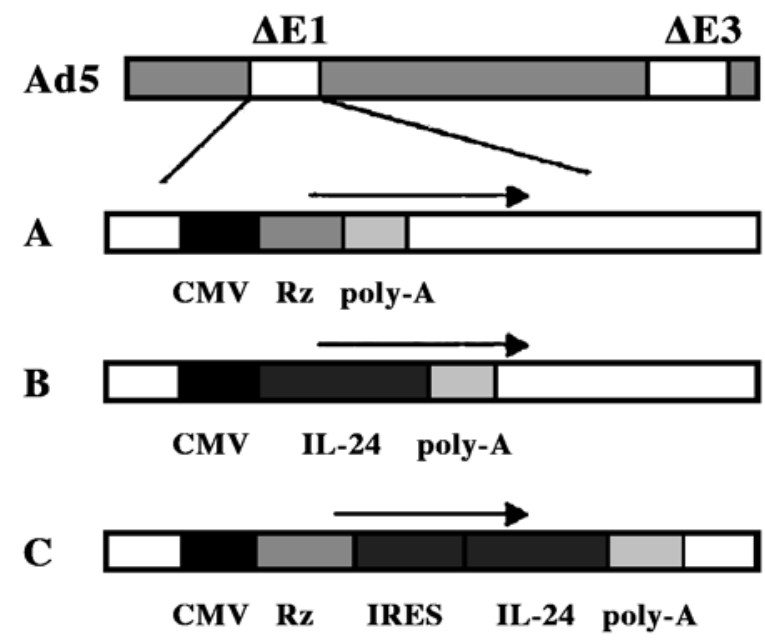

Figure 1. Schematic representation of the recombinant adenoviral vectors. An expression cassette containing (A) anti-VEGF ribozyme (Rz), (B) IL-24 and (C) anti-VEGF ribozyme + IL-24 (Rz/IL-24) was inserted into the deleted E1 region.

Table I. Infectivity of the Ad-GFP vector in HT-29 cells.

\begin{tabular}{cccccc}
\hline & \multicolumn{5}{c}{ MOI } \\
\cline { 2 - 5 } & 1 & 10 & 20 & 50 & \multirow{2}{*}{ PBS } \\
\hline Infection rate & $22.1 \pm 7.8$ & $61.6 \pm 1.1$ & $83.0 \pm 4.9$ & $97.4 \pm 0.5$ & $0.8 \pm 0.1$
\end{tabular}

MOI, multiplicity of infection. Data represent the mean volume \pm SD.

medium with $10 \%$ FBS was added. The ratio of adenovirusinfected cells with green fluorescence was measured using a flow cytometer $48 \mathrm{~h}$ after infection. The rate of successful adenovirus infection was $20 \%$ of HT-29 cells at $1 \mathrm{MOI}, 60 \%$ at $10 \mathrm{MOI}, 80 \%$ at $20 \mathrm{MOI}$ and $100 \%$ at $50 \mathrm{MOI}$ (Table I).

Expression of IL-24 and anti-VEGF hairpin ribozyme in HT-29 cells. Expression of anti-VEGF hairpin ribozyme and IL-24 mRNA was tested by RT-PCR. HT-29 cells were seeded in a $100-\mathrm{ml}$ dish and allowed to grow for $20 \mathrm{~h}$ before infection with Ad-Rz/IL-24, Ad-IL-24, Ad-Rz and Ad-GFP at 10 MOI, or with PBS. Total RNA from each group of cells was extracted with Trizol (Gibco-BRL, NY) $48 \mathrm{~h}$ after infection. Total RNA $(5 \mu \mathrm{g})$ was reverse-transcribed in a $20-\mu \mathrm{l}$ volume using MMoLV Reverse Transcriptase (Fermentas Life Science) according to the manufacturer's recommendations. Subsequently, PCR was performed with anti-VEGF hairpin ribozyme-specific primers (for Ad-Rz, sense 5'-GATAAGAATCCAACCAGA-3' and antisense 5'-TAAAGCAAGTAAAACCTC-3'; for Ad-Rz/ IL-24, sense 5'-TGATAAGAATCCAACCAGAG-3' and antisense 5'-AATGCTCGTCAAGAAGACA-3') andIL-24-specific primers (sense 5'-GCACTCGAGACCATGAATTTTCAAC AGAGGCTGCA-3' and antisense 5'-GCTTCTAGATCAGA GCTTGTAGAATTTCTG-3'). Amplification results were analyzed by $1.2 \%$ agarose gel electrophoresis and visualized under UV illumination after staining with ethidium bromide. 
Expression of IL-24 protein was evaluated by immunofluorescence staining. HT-29 cells, seeded on a coverslip in a 6-well plate, were infected with Ad-Rz/IL-24, Ad-IL-24, Ad-Rz and Ad-GFP at $10 \mathrm{MOI}$, or with PBS. After $48 \mathrm{~h}$, cells were fixed with $4 \%$ paraformaldehyde for $30 \mathrm{~min}$, rinsed three times with TBSTX (TBS containing 0.1\% Triton X-100), and blocked with 5\% BSA (diluted with TBSTX) for $60 \mathrm{~min}$. Subsequently, cells were stained with mouse anti-human IL-24 monoclonal antibody (R\&D Systems, clone 283123, VDN02) at a concentration of $25 \mu \mathrm{g} / \mathrm{ml}$ for $60 \mathrm{~min}$. After three washes with TBSTX, cells were incubated with Cy3-conjugated goat anti-mouse antibody (Beyotimem, China) at 1:500 for $30 \mathrm{~min}$ and then washed three times. Finally, after incubation with an anti-quenching agent, the coverslips were put on the slides, checked and photographed immediately under a fluorescence microscope (Nikon TE 2000, Japan).

Inhibition of VEGF expression. VEGF mRNA expression was semi-quantified by real-time PCR in cells infected with each adenovirus at $10 \mathrm{MOI}$ or with PBS. The primers used for VEGF amplification were sense 5'-GCCCACTGAGGAGTCC AACA-3' and antisense 5'-TCCTATGTGCTGGCCTTGGT-3', and probe 5'-FAM-CACCATGCAGATTATGCGGATCAAA CCTAMRA-3'. The primers for GAPDH were sense 5'-CCA CCCATGGCAAATTCC-3' and antisense 5'-TGGGATTTC CATTGATGACAAG-3' and probe 5'-FAMTGGCACCGT CAAGGCTGAGAACGTAMRA-3'. Real-time PCR was performed in a total reaction volume of $25 \mu \mathrm{l}$ per capillary. The amplification conditions consisted of an initial 5-min denaturation step at $94^{\circ} \mathrm{C}$, followed by 50 cycles of $95^{\circ} \mathrm{C}$ for $15 \mathrm{sec}$ and $60^{\circ} \mathrm{C}$ for $60 \mathrm{sec}$. To quantify the secreted VEGF protein in conditioned media from cells, human VEGF ELISA was performed using a human VEGF ELISA Kit (Boster, China) following the manufacturer's protocol with $100-\mu \mathrm{l}$ samples diluted 1:50.

Cell viability assay. Cell viability was assessed using MTT dye conversion. Cells (HT-29, LoVo and HUVEC304) were plated in 96-well plates and treated with the various adenoviruses or PBS. At the indicated time, medium was removed, and fresh medium containing $0.5 \mathrm{mg} / \mathrm{ml}$ MTT was added to each well. The cells were incubated at $37^{\circ} \mathrm{C}$ for $4 \mathrm{~h}$, and then an equal volume of solubilization solution $(0.01 \mathrm{~N} \mathrm{HCl}$ $+10 \%$ SDS) was added to each well to solubilize the reaction products overnight at $37^{\circ} \mathrm{C}$. The 96 -well plates were read on a plate reader (Molecular Probes, Sunnyvale, CA, USA). The assessments were conducted in triplicate.

Apoptosis assay. To measure cell apoptosis, $2 \times 10^{5}$ cells infected with each virus (10 MOI) or treated with PBS were gently trypsinized $48 \mathrm{~h}$ after infection, washed once with serum-containing media and suspended in $500 \mu \mathrm{l}$ of $1 \mathrm{X}$ binding buffer. Cells were then incubated with $5 \mu$ l Annexin V-PE (Biovision, USA) at room temperature for $5 \mathrm{~min}$ in the dark, followed by $10 \mu \mathrm{l}$ propidium iodide solution $(50 \mu \mathrm{g} / \mathrm{ml})$ for another $5 \mathrm{~min}$ at room temperature in the dark. Lastly, cells were analyzed using a flow cytometer.

Animal study. Female 4- to 5-week-old Balb/c nude mice from the Animal Research Committee of the Institute of
Biochemistry and Cell Biology (Shanghai, China) were used in this experiment. HT-29 cells $\left(2 \times 10^{6}\right)$ in $100 \mu 1$ of PBS were injected s.c. in the right flank of male nude mice. Each treatment group comprised 5 animals. After 7-15 days, visible tumors $\left(\sim 63.67 \pm 6.51 \mathrm{~mm}^{3}\right)$ were observed, and intratumoral injections of different adenoviruses were administered at a dose of $1 \times 10^{8} \mathrm{MOI}$ in $50 \mu \mathrm{l}$ PBS. The injections were given 3 times/ week for 3 weeks. Tumor volume was measured weekly with a caliper and calculated using the formula: volume $=\left(1 \mathrm{x} \mathrm{w}^{2}\right) / 2$ (where 1 is the diameter of the length and $w$ is the widest diameter). The tumor proliferation rate (PR) was calculated using the formula:

$$
\mathrm{PR}=\frac{\text { volume }_{(\text {after treatment) }}-\text { volume }_{\text {(before treatment) }}}{\text { volume }_{\text {(before treatment) }}}
$$

At the end of the experiment, the tumors were harvested for immunohistochemical analysis.

Immunohistochemical analysis. Tumors were harvested and fixed with cold acetone. Endogenous peroxidase activity was blocked by treating the tissue with $3 \% \mathrm{H}_{2} \mathrm{O}_{2}$ in methanol for $10 \mathrm{~min}$. The sections were then incubated with the primary anti-IL-24 antibodies (R\&D Systems, clone 283123, VDN02), or CD34 antibodies (BA0532, Boster, China). The secondary antibody was avidin-labeled anti-mouse IgG. The biotinylated horseradish peroxidase avidin-biotin complex reagent was used to detect the antigen-antibody complex in diaminobenzidine tetrahydrochloride solution. All sections were counterstained with hematoxylin. The sections were then evaluated for the presence of brown diaminobenzidine precipitates by light microscopy, and microvessel density (MVD) was assessed using the Chalkley method previously described in detail (20) by counting the microvessels (at x200 in three fields) that had the highest vascularization by scanning at x100.

Statistical analysis. Data were presented as the mean \pm SD of three independent experiments. The statistical significance was determined using analysis of variance, with $\mathrm{P}<0.05$ considered to be statistically significant.

\section{Results}

Transduction of anti-VEGF ribozyme and IL-24 into HT-29 cells. As assayed by RT-PCR, cells infected with Ad-Rz/IL-24 and $\mathrm{Ad}-\mathrm{Rz}$ exhibited expression of anti-VEGF ribozyme RNA, and cells infected with Ad-IL-24 and Ad-Rz/IL-24 exhibited IL-24 RNA expression (Fig. 2A). Cells infected with Ad-GFP or PBS exhibit neither anti-VEGF ribozyme RNA nor IL-24 mRNA expression. The results of immunofluorescence staining with a monoclonal antibody specific for IL-24 protein are shown in Fig. 2B. Strong red fluorescence was observed in cells after infection with Ad-IL-24 and Ad-Rz/IL-24, but no fluorescence was observed in cells infected with PBS, Ad-Rz or Ad-GFP.

Inhibition of VEGF mRNA expression and reduction of VEGF protein secretion from infected HT-29 cells. Real-time PCR results showed that the expression of VEGF mRNA in HT-29 cells treated with Ad-Rz/IL-24, Ad-Rz and Ad-IL-24 was 
A.
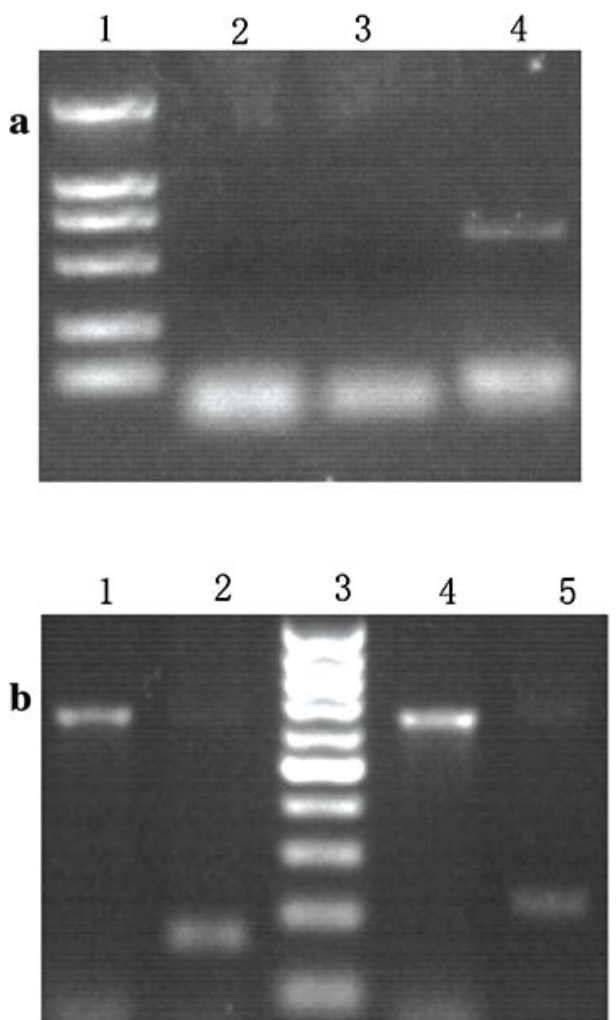

B.
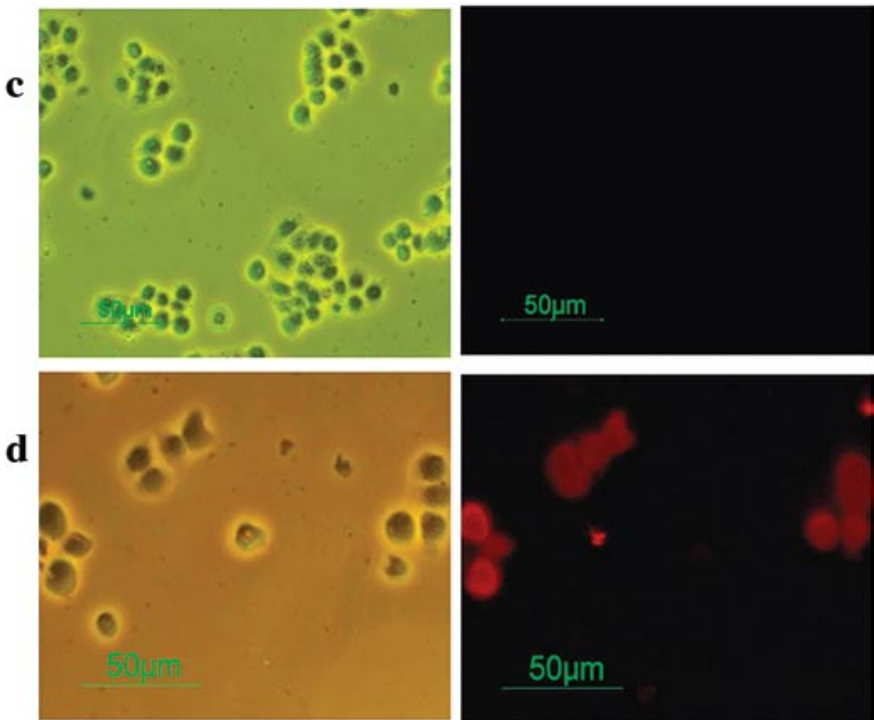

e
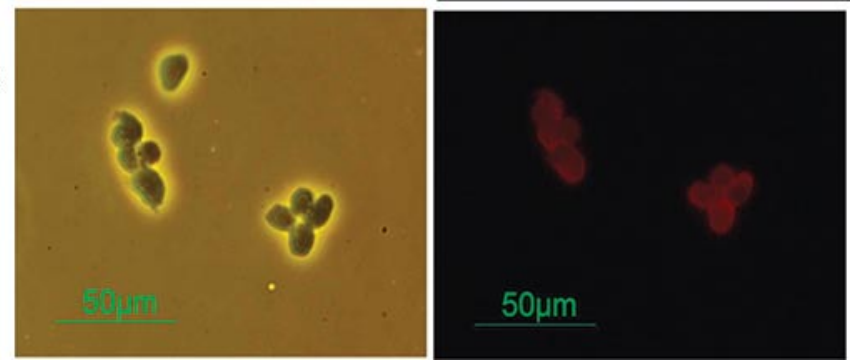

Figure 2. Expression of anti-VEGF ribozyme RNA and IL-24 mRNA and protein in viral infected HT-29. A: (a) RT-PCR demonstrated that HT-29 cells did not express IL-24. Lane 1, marker; lane 2, cDNA from untreated HT-29 cells where no IL-24 expression was noted; lane 3, negative control, PCR for plasmid of pTrack-CMV-Rz; and lane 4, positive control, PCR for plasmid of pTrack-CMV-IL-24. A 621-bp DNA fragment was noted. (b) RT-PCR analysis of the expression of anti-VEGF ribozyme and IL-24 RNA in HT-29 cells. Lane 1, IL-24 in cells infected with Ad-IL-24; lane 2, anti-VEGF ribozyme with an expected length of 162 bp in cells infected with Ad-Rz; lane 3, marker; lane 4, IL-24 in cells infected with Ad-Rz/IL-24; and lane 5, anti-VEGF ribozyme in cells infected with Ad-Rz/IL-24 with an expected length of 214 bp. B: Results of immunofluorescence staining of IL-24 protein expression in cells treated with (c) PBS, (d) Ad-IL-24 and (e) Ad-Rz/IL-24. Left, light microscopy; right, fluorescence microscopy.

A.

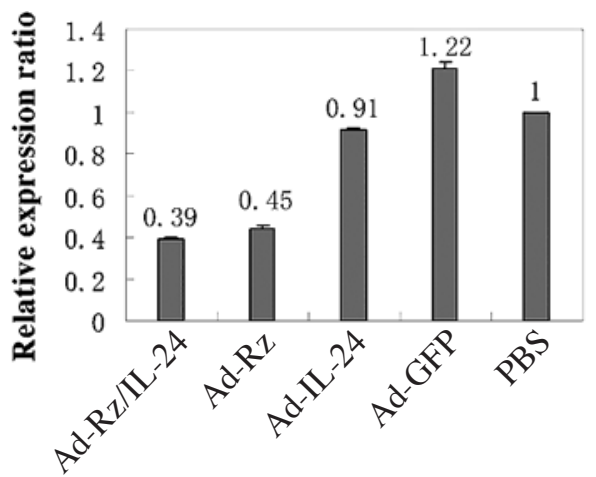

B.

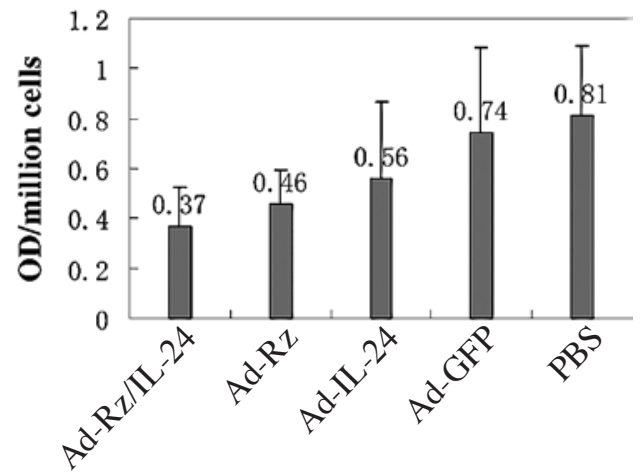

downregulated in comparison with cells tre ated with PBS. The relative quantity of VEGF mRNA expression was the lowest in Ad-Rz/IL-24-treated cells (Fig. 3A). We also investigated the VEGF protein concentration in conditioned medium. As shown in Fig. 3B, the expression of VEGF protein was also suppressed by infecting cells with Ad-Rz/IL-24, Ad-Rz or Ad-IL-24. The relative expression ratio (compared to PBS) was $45.7 \%(0.37 / 0.81, \mathrm{P}<0.05), 56.8 \%(0.46 / 0.81, \mathrm{P}<0.05)$ and $69.1 \%(0.56 / 0.81, \mathrm{P}>0.05)$, respectively. VEGF expression in cells treated with Ad-GFP was $91.6 \%(0.74 / 0.81, \mathrm{P}>0.05)$.

Inhibiting VEGF and IL-24 reduces tumor cell viability. The growth inhibitory effect in the colon cancer cell lines HT-29 and LoVo and the normal cell line HUVEC304 was assessed by measuring cell viability. Cells were infected with each adenoviral vector encoding a therapeutic gene or Ad-GFP at 10 or 50 MOI, or with PBS (Fig. 4). Daily analysis for cell viability by MTT assay showed significant growth inhibition for colon

Figure 3. Cells treated with Ad-Rz/IL-24, Ad-IL-24 and Ad-Rz expressed reduced levels of VEGF. (A) Real-time PCR results, (B) ELISA results of VEGF protein secretion. 

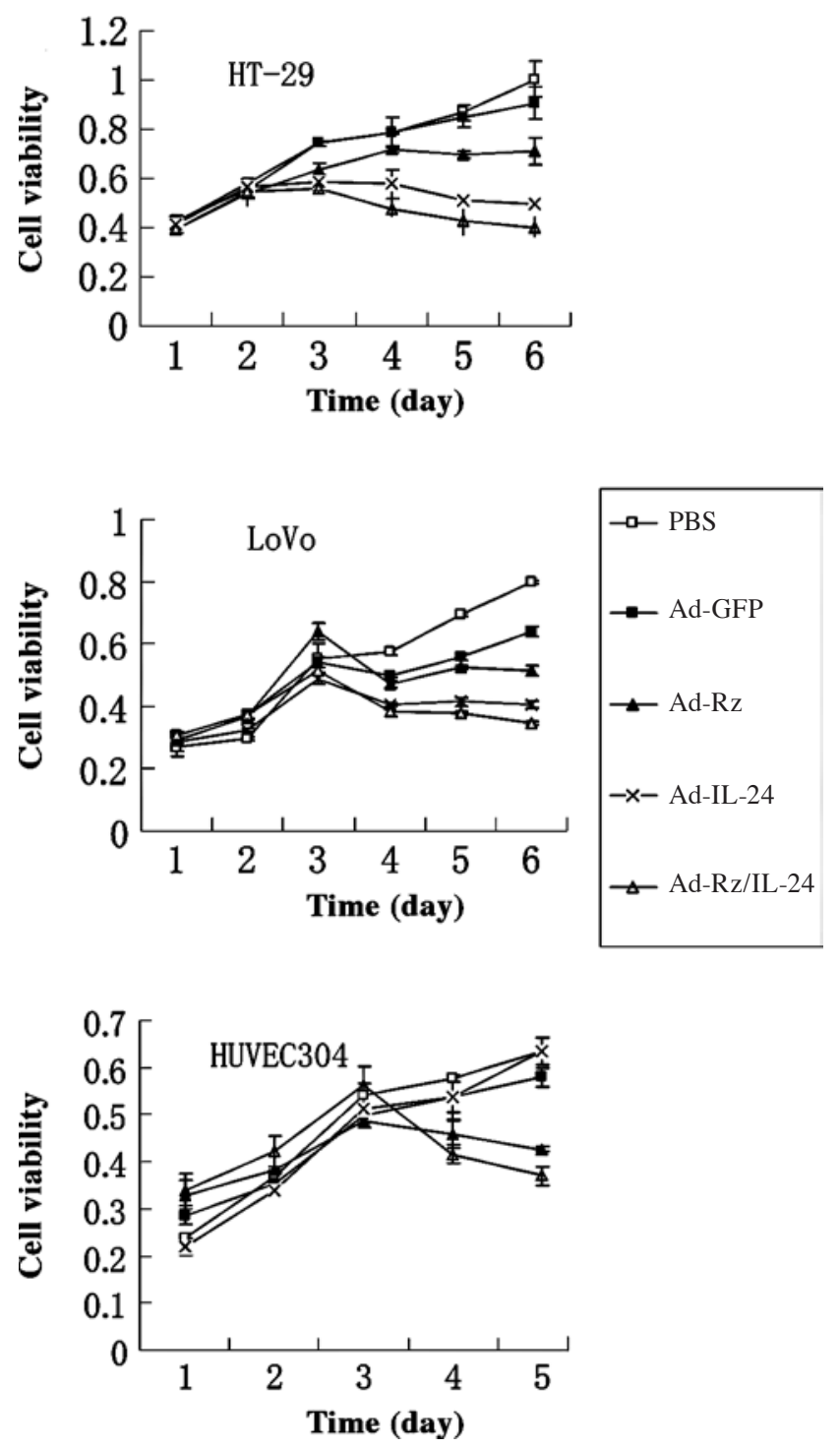

Figure 4. Cell viability assay by MTT after treatment with adenovirus and PBS. The OD value at each point is the mean \pm SD of three different wells. Triplicate experiments were performed for each cell line. Marked cell growth inhibition was demonstrated by Ad-Rz/IL-24 and Ad-IL-24 in the colon cancer cells HT-29 and LoVo. In the normal cell line, HUVEC304, marked cell growth inhibition was demonstrated by Ad-Rz/IL-24 and Ad-Rz, while Ad-IL-24 had only a mild effect on cell growth.

cancer cell lines by Ad-Rz/IL-24 or Ad-IL-24 ( $\mathrm{P}<0.05$ compared to PBS), while cells treated with Ad-Rz did not show significant growth inhibition $(\mathrm{P}>0.05)$. Growth of the normal cell line HUVEC304 was significantly inhibited by Ad-Rz/ IL-24 and Ad-Rz $(\mathrm{P}<0.05)$, but not by Ad-IL-24 $(\mathrm{P}>0.05)$. When treated with each adenovirus at $50 \mathrm{MOI}$, cells showed markedly increased growth inhibition. However, cell viability was not affected by any of the four adenoviruses.

Effects on apoptosis of HT-29 cells. After treatment for $48 \mathrm{~h}$, cells were harvested and apoptotic cells were measured by flow cytometry. Ad-Rz/IL-24 treatment induced apoptosis in $\sim 11 \pm 0.8 \%$ of the cells, approximately twice as many as those affected by Ad-IL-24 (5.6 $\pm 0.3 \%)$ treatment. Ad-Rz treatment induced apoptosis in only $\sim 1.8 \pm 0.2 \%$ of the cells, but was still

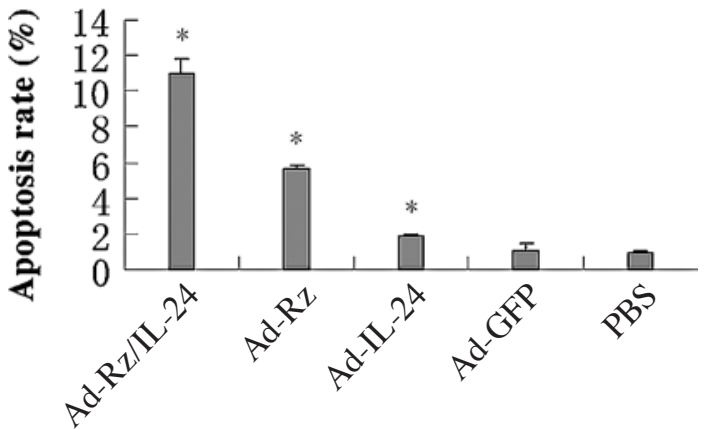

Figure 5. The percentage of apoptotic cells induced by each adenovirus. Data are presented as the mean $\pm \mathrm{SD}$ of three experiments. ${ }^{*} \mathrm{P}<0.05$.

Table II. The proliferation rate of xenograft tumors and the microvascular density of xenografts obtained from angiogenic maker CD34 staining.

\begin{tabular}{lcc}
\hline & Tumor proliferation rate & MVD \\
\hline PBS & $4749.3 \pm 4898.3$ & $12.8 \pm 11.1$ \\
Ad-GFP & $3911.1 \pm 1860.8$ & $11.5 \pm 1.0$ \\
Ad-IL-24 & $2086.7 \pm 295.1$ & $6.0 \pm 1.0^{\mathrm{b}}$ \\
Ad-Rz & $2413.5 \pm 2105.6$ & $4.3 \pm 0.5^{\mathrm{b}}$ \\
Ad-Rz/IL24 & $1127.1 \pm 1109.3^{\mathrm{a}}$ & $3.5 \pm 0.6^{\mathrm{b}}$ \\
\hline
\end{tabular}

MVD, microvascular density. Data are presented as the mean \pm SD. ${ }^{\mathrm{a}} \mathrm{P}=0.0619,{ }^{\mathrm{b}} \mathrm{P}<0.05$ compared to PBS.

significantly different from both the control $(\mathrm{P}=0.004)$ and Ag-GFP-treated cells $(\mathrm{P}=0.042)$. The apoptosis rate induced by Ad-GFP did not differ from the rate induced by PBS $(\mathrm{P}=0.303)$ (Fig. 5).

Inhibition of tumor growth and angiogenesis in vivo. Based on the evaluation of the tumor-inhibiting efficacy of Ad-Rz/IL-24, the growth of xenograft tumors was inhibited by Ad-Rz/IL24 treatment, but with borderline significance only $(\mathrm{P}=0.0619$, $\mathrm{CMH}$ test, compared to PBS). No significant inhibitory effect was had on tumor growth by Ad-IL-24 or Ad-Rz treatment alone. (Table II). The histology of the tumors in each group was examined by light microscopy. The microvascular content of the tumor was evaluated by CD34 staining and MVD counting (Table II). The vasculature of tumors treated with PBS and Ad-GFP was tortuous and dilated with disproportionate branching compared with the other three groups (Fig. 6A. The Ad-Rz/IL-24-treated tumors had the smallest MVD count of all the groups. IL-24 protein was detected only in the Ad-Rz/ IL-24- and Ad-IL-24-treated groups (Fig. 6B).

\section{Discussion}

The occurrence of tumors is a multiple-gene alteration event. In the rapidly developing field of cancer gene therapy, the inhibition of oncogenic activity and the augmentation of tumor-suppressor gene activities have been extensively examined. However, the therapeutic efficacy of either of 
A.
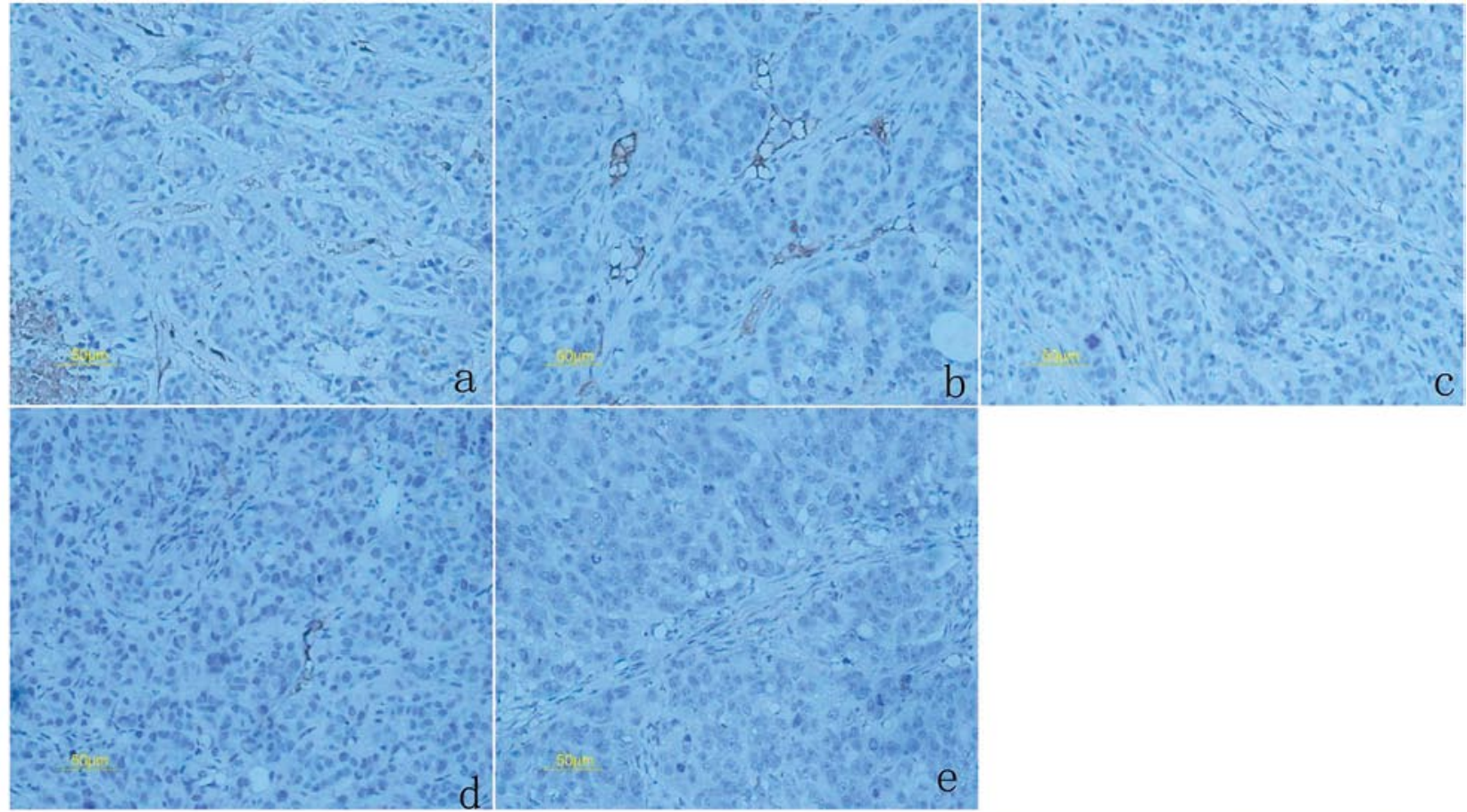

B.
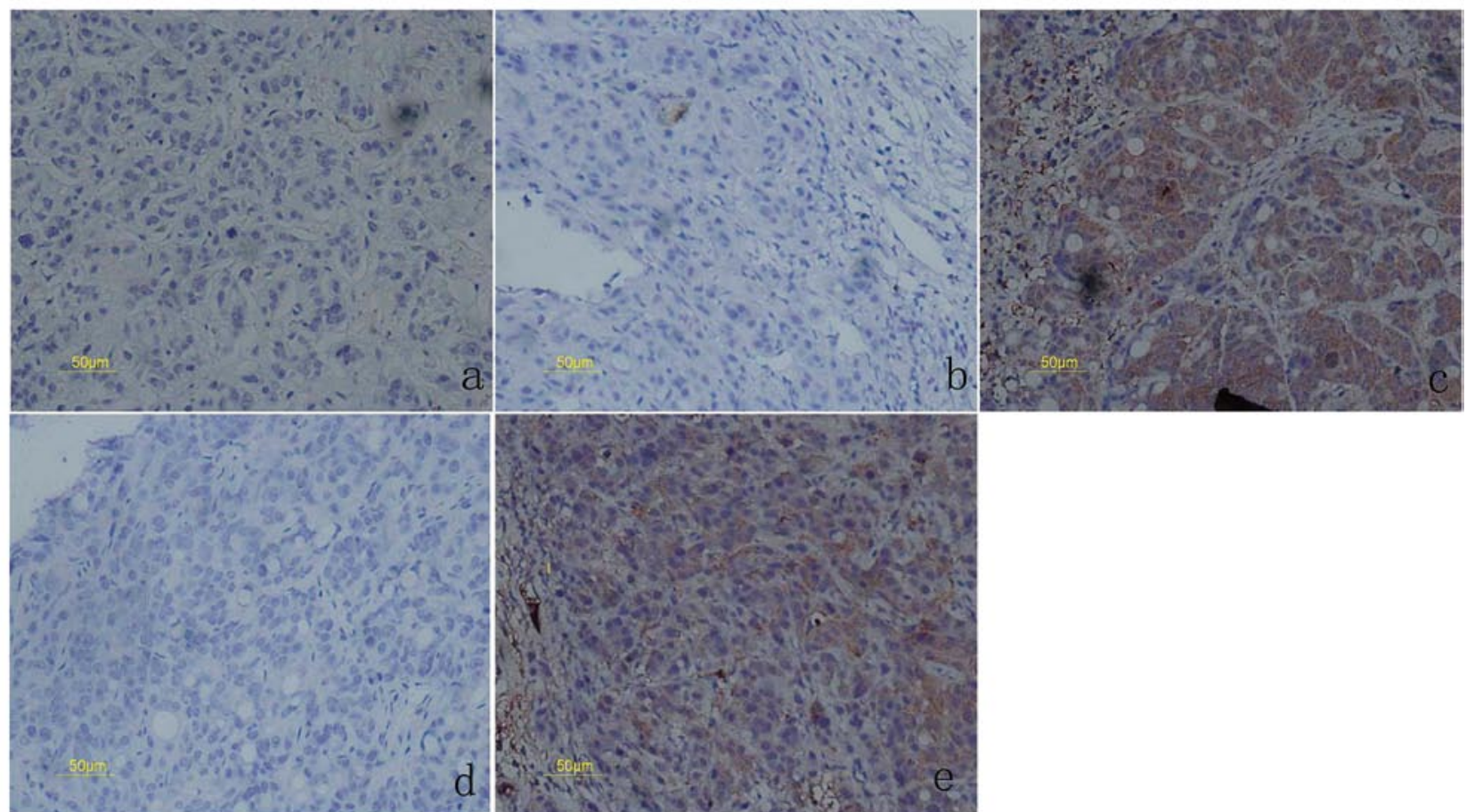

Figure 6. A: Vascular staining in HT-29 xenograft tumors. Photomicrographs of immunohistochemical staining with an anti-CD34 mAb (x200). Representative areas are from tumors receiving (a) PBS treatment, (b) Ad-GFP, (c) Ad-IL-24, (d) Ad-Rz and (e) Ad-Rz/IL-24. B: Immunohistochemical staining with an antiIL-24 mAb. IL-24 expression is noted in tumor sections from mice receiving (c) Ad-IL-24 and (e) Ad-Rz/IL-24 treatment, and no IL-24 expression is noted in the other three groups (a, PBS; b, Ad-GFP; and d, Ad-Rz).

these strategies alone may not be sufficient to control cancer growth. Researchers have begun testing the therapeutic efficacy of simultaneous treatment with two or more antitumor genes with different properties. Some studies have revealed that significant tumor inhibition can be obtained by the combined use of two different genes, for example, the combination of TRAIL and IL-24 against colon cancer (21), or of wild-type $\mathrm{p} 53$ and anti-erbB2 ribozyme against bladder cancer (22).
In this study, we constructed a recombinant adenovirus that simultaneously encodes two therapeutic genes, anti-VEGF hairpin ribozyme and human IL-24. These two genes were linked through an IRES (internal ribosome entry site) and inserted into a serotype 5, E1/E3-deleted adenovirus driven by the CMV promoter. As the name indicates, the IRES allows the ribosome to initiate translation internally rather than at the 5'-end of the mRNA (23). In 1992, Morgan and colleagues first used an IRES to assemble a two- or three-gene retroviral 
vector (24). Since then, the IRES has been used to construct vectors carrying multiple genes, negating the need for multiple promoter elements. The CMV promoter is a strong constitutive promoter for the continuous expression of transgenes. The maximum insert size for the pAdTrack-CMV/pAdEasy-1 vector system is approximately $5.0 \mathrm{~kb}(17)$, and the anti-VEGF ribozyme-IRES-IL-24 sequence is less than $1.5 \mathrm{~kb}$. The CMV promoter should efficiently drive the expression of these two genes. In fact, in this study, the results of the RT-PCR and immunofluorescence staining demonstrate that the recombinant viral vectors sufficiently expressed the genes harbored in them and directed the biosynthesis of IL-24 protein in tumor cells (Fig. 2).

The therapeutic efficacy of anti-oncogenic ribozymes has been extensively demonstrated in vitro and in vivo (25-27). The hairpin ribozyme is a small RNA molecule with endoribonuclease activity that exhibits catalytic sequence-specific cleavage of the target RNA by first hybridizing to it through a complementary 'arm' sequence, then cleaving it with a conserved central catalytic region. The hairpin ribozyme is easy to design, and its activity is independent of metal ions or other catalytic cofactors (28). A number of strategies to inhibit VEGF are in development. The two main classes of inhibitors consist of agents designed to inhibit ligand activity or receptor function. The anti-VEGF hairpin ribozyme inhibits ligand activity by downregulating the expression of VEGF mRNA. Marked downregulation of both mRNA and the encoded protein for VEGF was obtained in HT-29 cells by means of the transduction of anti-VEGF ribozyme by Ad-Rz/ IL-24 and Ad-Rz, but the inhibition efficiency of Ad-Rz/IL-24 was stronger. Ad-IL-24 also showed anti-VEGF activity, but its inhibitory effect was mild and weaker than that of Ad-Rz/ IL-24 and Ad-Rz.

In vitro, colon cancer cell lines infected with Ad-Rz/IL-24 or Ad-IL-24 showed a significant reduction in cell viability and increased apoptosis compared to cells treated with PBS, while Ad-Rz resulted in only a mild reduction in viability and increase in apoptosis. On the other hand, downregulating VEGF by Ad-Rz/IL-24 and Ad-Rz caused remarkable growth inhibition in the normal cell line HUVEC304 (Fig. 4), since VEGF is necessary for the proliferation and survival of vascular endothelial cells. In vivo, encouraging results were obtained in nude mice studies. Tumor growth and angiogenesis (MVDCD34) in xenografts were suppressed by Ad-Rz/IL-24, and the proliferation rate of tumors treated with Ad-Rz/IL-24 was approximately $50 \%$ less than the rate observed with Ad-IL-24 or Ad-Rz treatment. This suggests that Ad-Rz/IL-24 has a synergistic tumor inhibitory effect: anti-angiogenesis by antiVEGF hairpin ribozyme and apoptosis induction by IL-24. Although VEGF is a multifunctional cytokine, its main functions involve angiogenesis and vascular permeability (29). Ad-Rz suppressed tumor growth mainly through the inhibition of tumor angiogenesis. This explains why Ad-Rz could not suppress tumor growth in vitro.

There is increasing evidence that IL-24 has potent growth suppression and apoptosis induction activities in many different types of tumor cells, while sparing normal cells (30-33). Furthermore, certain studies have demonstrated that IL-24 also has the ability to inhibit angiogenesis, and that this effect is dependent on the IL-22 receptor (34). Our results show that
Ad-IL-24 mildly inhibited the expression of VEGF mRNA and protein in HT-29 cells.

Cellular apoptosis can also be induced by replicationcompetent adenoviruses (RCAs). To avoid the emergence of RCAs (35), we detected the expression of E1a by RT-PCR in all groups, and did not find the expression of the E1 gene.

In conclusion, we constructed a dual-gene-expressing adenoviral vector, Ad-Rz/IL-24. The results show that Ad-Rz/ IL-24 significantly inhibited VEGF expression and angiogenesis in vitro and in vivo. Due to the upregulation of VEGF in most human tumors, examining the antitumor activity of Ad-Rz/ IL-24 in other tumor types is warranted.

\section{Acknowledgements}

This study was supported by grants from the Outstanding Medical Academic Program of Jiangsu Province, China (no. RC2007076).

\section{References}

1. Folkman J: What is the evidence that tumors are angiogenesis dependent? J Natl Cancer Inst 82: 4-6, 1990.

2. Folkman J: Role of angiogenesis in tumor growth and metastasis. Semin Oncol 129: 111-119, 2002.

3. Reinmuth N, Parikh AA, Ahmad SA, Liu W, Stoeltzing O, Fan F, Takeda A, Akagi M and Ellis LM: Biology of angiogenesis in tumors of the gastrointestinal tract. Microse Res Tech 60: 199-207, 2003.

4. Lee JC, Wang ST, Chow NH and Yang HB: Prognostic value of vascular endothelial growth factor expression in colorectal cancer patients. Eur J Cancer 36: 748-753, 2002.

5. Takahashi Y, Kitadai Y, Bucana CD, Cleary KR and Ellis LM: Expression of vascular endothelial growth factor and its receptor, KDR, correlates with vascularity, metastasis, and proliferation of human colon cancer. Cancer Res 55: 3964-3968, 1995.

6. Wong MP, Cheung N, Yuen ST, Leung SY and Chung LP: Vascular endothelial growth factor is up-regulated in the early pre-malignant stage of colorectal tumor progression. Int J Cancer 81: 845-850, 1999.

7. Pestka S, Krause CD, Sarkar D, Walter MR, Shi Y and Fisher PB: Interleukin-10 and related cytokines and receptors. Annu Rev Immunol 22: 929-979, 2004.

8. Jiang H, Lin JJ, Su ZZ, Goldstein NI and Fisher PB: Subtraction hybridization identifies a novel melanoma differentiation associated gene, mda-7, modulated during human melanoma differentiation, growth and progression. Oncogene 11:2477-2486, 1995.

9. Gupta P, Su ZZ, Lebedeva IV, et al: Mda-7/IL-24: multifunctional cancer-specific apoptosis-inducing cytokine. Pharmacol Ther 111: 596-628, 2006.

10. Madireddi MT, Su ZZ, Young CS, Goldstein NI and Fisher PB: Mda-7, a novel melanoma differentiation-associated gene with promise for cancer gene therapy. Adv Exp Med Biol 465: 239-261, 2000.

11. Jiang H, Su ZZ, Lin JJ, Goldstein NI, Young CS and Fisher PB: The melanoma differentiation-associated gene mda-7 suppresses cancer cell growth. Proc Natl Acad Sci USA 93: 9160-9165, 1996.

12. Lebedeva IV, Su ZZ, Chang Y, Kitada S, Reed JC and Fisher PB: The cancer growth suppressing gene mda-7 induces apoptosis selectively in human melanoma cells. Oncogene 21: 708-718, 2002.

13. Su ZZ, Lebedeva IV, Sarkar D, et al: Melanoma differentiation associated gene-7, mda-7/IL-24, selectively induces growth suppression, apoptosis and radiosensitization in malignant gliomas in a p53-independent manner. Oncogene 22: 1164-1180, 2003.

14. Fathallah-Shaykh HM, Zhao LJ, Kafrouni AI, Smith GM and Forman J: Gene transfer of IFN- $\gamma$ into established brain tumors represses growth by antiangiogenesis. J Immunol 164: 217-222, 2000.

15. O'Reilly MS, Boehm T, Shing Y, et al: An endogenous inhibitor of angiogenesis and tumor growth. Cell 88: 277-285, 1997. 
16. Yokoi K, Thaker PH, Yazici S, et al: Dual inhibition of epidermal growth factor receptor and vascular endothelial growth factor receptor phosphorylation by AEE788 reduces growth and metastasis of human colon carcinoma in an orthotopic nude mouse model. Cancer Res 65: 3716-3725, 2005.

17. He TC, Zhou S, Da Costa LT, Yu J, Kinzler KW and Vogelstein B: A simplified system for generating recombinant adenoviruses. Proc Natl Acad Sci USA 95: 2509-2514, 1998

18. Wang X, Ye Z, Zhong J, Xiang J and Yang J: Adenovirus-mediated IL-24 expression suppresses hepatocellular carcinoma growth via induction of cell apoptosis and cycling arrest and reduction of angiogenesis. Cancer Biother Radiopharm 22: 56-63, 2007.

19. Beger C, Kruger M and Wong-Staal F: Ribozyme in cancer gene therapy. In: Gene Therapy of Cancer. Lattime EC and Gerson SL (eds). 2nd Health Science Asia, Elsevier Science, pp95-108, 2002.

20. Vermeulen PB, Gasparini G, Fox SB, et al: Second international consensus on the methodology and criteria of evaluation of angiogenesis quantification in solid human tumours. Eur J Cancer 38: 1564-1579, 2002.

21. Zhao L, Dong A, Gu J, et al: The antitumor activity of TRAIL and IL-24 with replicating oncolytic adenovirus in colorectal cancer. Cancer Gene Ther 13: 1011-1022, 2006.

22. Irie A, Matsumoto $\mathrm{K}$, Anderegg $\mathrm{B}$, et al: Growth inhibition efficacy of an adenovirus expressing dual therapeutic genes, wild-type $\mathrm{p} 53$, and anti-erbB2 ribozyme, against human bladder cancer cells. Cancer Gene Ther 13: 298-305, 2006

23. Baird SD, Turcotte M, Korneluk RG and Holcik M: Searching for IRES. RNA 12: 1755-1785, 2006.

24. Morgan RA, Couture L, Elroy-Stein O, Ragheb J, Moss B and Anderson WF: Retroviral vectors containing putative internal ribosome entry sites: development of a polycistronic gene transfer system and applications to human gene therapy. Nucleic Acids Res 20: 1293-1299, 1992.

25. Wright L, Wilson SB, Milliken S, Biggs J and Kearney P: Ribozyme-mediated cleavage of the bcr/abl transcript expressed in chronic myeloid leukemia. Exp Hematol 21: 1714-1718, 1993.
26. Kashani-Sabet M, Funato $T$, Florenes VA, Fodstad $O$ and Scanlon KJ: Suppression of the neoplastic phenotype in vivo by an anti-ras ribozyme. Cancer Res 54: 900-902, 1994.

27. Wang CH, Tsai LJ, Tsao YP, et al: Recombinant adenovirus encoding H-ras ribozyme induces apoptosis in laryngeal cancer cells through caspase and mitochondria-dependent pathways. Biochem Biophys Res Commun 298: 805-814, 2002.

28. Adrian R and Ferre-D'Amare: The hairpin ribozyme. Biopolymers 73: 71-78, 2004

29. Frumovitz M and Sood AK: Vascular endothelial growth factor (VEGF) pathway as a therapeutic target in gynecologic malignancies. Gynecol Oncol 104: 768-778, 2007.

30. Gopalan B, Shanker M and Chada S: MDA-7/IL-24 suppresses human ovarian carcinoma growth in vitro and in vivo. Mol Cancer 6: 11-12, 2007.

31. Saeki T, Mhashilkar A, Chada S, Branch C, Roth JA and Ramesh R: Tumor-suppressive effects by adenovirus-mediated mda-7 gene transfer in non-small cell lung cancer cell in vitro. Gene Ther 7: 2051-2057, 2000.

32. Saeki T, Mhashilkar A, Swanson X, et al: Inhibition of human lung cancer growth following adenovirus-mediated mda-7 gene expression in vivo. Oncogene 21: 4558-4566, 2002.

33. Chada S, Sutton RB, Ekmekcioglu S, et al: MDA-7/IL-24 is a unique cytokine-tumor suppressor in the IL-10 family. Int Immunopharmacol 4: 649-667, 2004.

34. Inoue S, Branch CD, Gallick GE, Chada S and Ramesh R: Inhibition of Src kinase activity by Ad-mda7 suppresses vascular endothelial growth factor expression in prostate carcinoma cells. Mol Ther 12: 707-715, 2005.

35. Zhu JD, Grace M, Casale J, et al: Characterization of replicationcompetent adenovirus isolates from large-scale production of a recombinant adenoviral vector. Hum Gene Ther 10: 113-121, 1999. 